\title{
Unilateral Palmoplantar Keratoderma: A Rare Case Report
}

\author{
Authors \\ Mudita Gupta ${ }^{1}$, Saru Thakur ${ }^{2 *}$, Reena Kumari Sharma ${ }^{3}$, KuldeepVerma ${ }^{4}$, \\ Samriti Sood ${ }^{5}$ \\ ${ }^{1}$ Assistant Professor, ${ }^{2,4,5}$ Post graduate student, ${ }^{3}$ Senior Resident \\ Deptt. of Dermatology, Leprosy and Venereology, Indira Gandhi Medical College, Shimla \\ *Corresponding Author

\section{Saru Thakur} \\ Deptt. of Dermatology, Leprosy and Venereology, Indira Gandhi Medical College, Shimla,
}

Himachal Pradesh, India

\begin{abstract}
Palmoplantar keratodermas (PPK) are heterogenous group of disorders characterized by epidermal hyperkeratosis involving the palms and the soles. Clinically, PPK present in diffuse, focal or punctate forms. A single case report of unilateral diffuse PPK is present in literature. We are reporting a 19 years old female patient of unilateral diffuse PPK present since childhood, with no systemic abnormalities or associated keratinization disorders.

Keywords: palmoplantar keratoderma, unilateral, diffuse, fissuring.
\end{abstract}

\section{Introduction}

Hereditary palmoplantar keratodermas (PPK) comprise a clinically and genetically heterogeneous group of disorders characterized by impaired epidermal differentiation leading to marked palmoplantar hyperkeratosis. Clasically, keratodermas have been classified as hereditary or acquired forms. Inherited forms are further grouped as syndromic or non-syndromic PPKs. Based on clinical picture, PPK can be diffuse, focal or punctate in appearance ${ }^{(1)}$. The epidermal thickening manifests bilaterally usually involving both palms and, or soles. The presentation in unilateral palm or sole has rarely been reported in five cases of striate or linear PPK and only a single case report of diffuse form. We are reporting this case of unilateral diffuse PPK due to rarity and as the second case of unilateral diffuse PPK.

\section{Case Report}

A 19 years old female, presented to the dermatology OPD with diffuse thickening, yellowish discoloration of her right sole since childhood (Figure 1). Presently, she was complaining of pain due to fissuring on the sole and discomfort on walking. There was no history of similar lesions or complaints in the family members and was born of a non- consanguineous marriage. On examination, there was a thick yellow-colored plaque of size $10 \times 7 \mathrm{~cm}$ approximately, with superficial and deep fissures covering the distal half of the right sole, more prominent on the great toe. It was non- 
transgradient PPK limited to plantar aspect only. No similar lesions were observed on other parts of the body. The palms and left sole showed no hyperkeratosis. Histopathological examination of the skin biopsy specimen demonstrated marked hyperkeratosis. There were no abnormalities of the hair, nails, mucosa and no associated disorders of keratinization. There were no systemic symptoms or signs pertaining to syndromic forms of PPK. The patient was finally diagnosed as a case of unilateral diffuse plantar keratoderma. There was no history of any preceding trauma or inflammatory lesions.

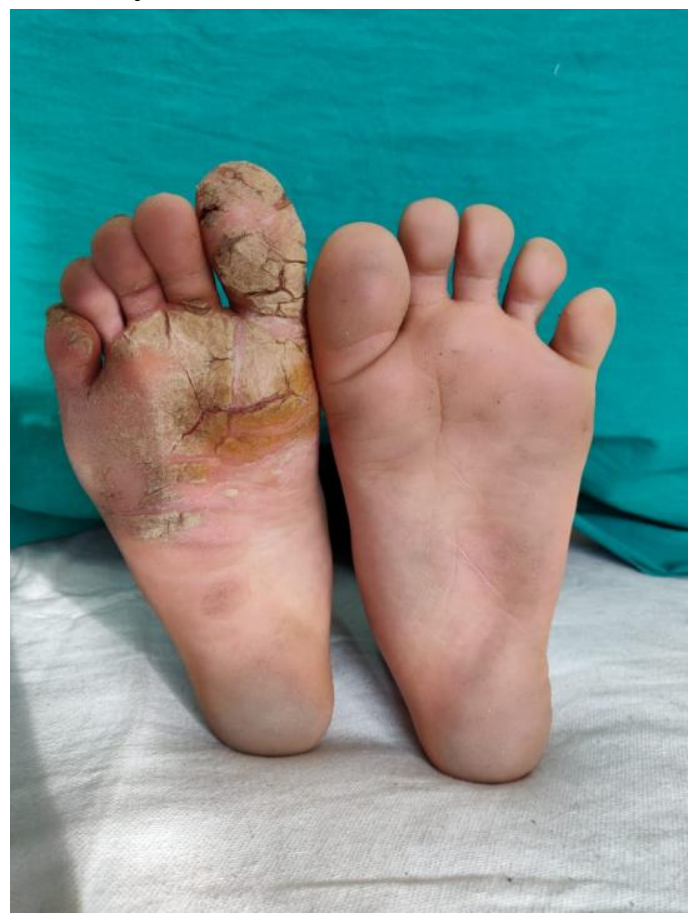

Figure 1: Unilateral plantar keratoderma seen on the plantar surface of right sole.

\section{Discussion}

Palmoplantar keratodermas (PPKs) are a heterogeneous group of genodermatoses characterized by epidermal thickening of the palms and soles. The hyperkeratosis may be restricted to palms and soles, or be associated with generalized disorders of keratinization or systemic abnormalities in the syndromic forms. The exact etiology of PPKs is not known. Autosomal recessive, autosomal dominant, X-linked inheritance and acquired forms have been described in literature ${ }^{(2)}$.

Clinically, diffuse, focal, and punctate forms of
PPK have been described. But since the past two decades, increasing defects are being studied by molecular genetic analysis allowing classification of PPK thereof, based on the defects in keratins, loricrin, desmosomes, connexins and cathepsins. In our patient, clinical examination and history lead to diagnosis and genetic studies could not be done due to non-availability.

Hereditary PPKs generally manifest bilaterally. However, very few authors have reported unilateral PPK. Sharma et $\mathrm{al}^{(3)}$ reported PPK in right palm and sole, Karabacack et $\mathrm{al}^{(4)}$ in left palm and sole, Ozkaya et $\mathrm{al}^{(5)}$ in right palm, Arif et $\mathrm{al}^{(6)}$ in right sole. Kiatsurayanon et $\mathrm{al}^{(1)}$ observed PPK in right sole. However, all these patients had punctate epidermal hyperkeratosis. It was Okan et $\mathrm{al}^{(2)}$, who reported unilateral involvement of sole in diffuse form of PPK in 2014. Our patient is the second case of diffuse palmoplantar keratoderma manifesting unilaterally, to the best of our knowledge. It has been proposed that genetic mosaicism accounts for the unilateral nature of the lesions in inherited disorders, which otherwise manifests bilaterally.

Treatment of keratodermas is generally symptomatic including saltwater soaks, paring, topical keratolytics to specific therapies such as systemic retinoids, psoralens and ultraviolet $\mathrm{A}$ (PUVA) and re-PUVA. When symptomatic therapy does not work, reconstructive surgery may be done with total excision of the hyperkeratotic skin followed by grafting ${ }^{(6)}$.

\section{Conclusion}

Palmoplantar keratodermas manifest as bilateral epidermal thickening of palms and soles. Unilateral involvement of otherwise bilateral PPK has been reported very rarely. We are reporting the second case of unilateral plantar keratoderma due to rarity of its occurrence.

Conflict of Interest: Nil.

Sources of support: nil 


\section{References}

1. Kiatsurayanon C, Rojanamatin J, Sudtikoonaseth P, Kampirapap K, Wichaidit M, Niyonsaba F. Unilateral Linear Punctate Palmoplantar Keratoderma: A Case Report. Case Rep Dermatol. 2017; 9:86-89. DOI: 10.1159/ 000468920

2. Okan G, Tekin B, Büyükbabani N, Yücelten AD. Unilateral diffuse plantar keratoderma: An example of cutaneous mosaicism? Cumhuriyet Med J. 2015; 37(1): 65-6.

3. Sharma S, Barman KD, Garg VK, Jain S. Unilateral linear punctate palmoplantar keratoderma. Indian J Dermatol Venereol Leprol 2012;78:85- 8 .

4. Karabacak E, Kucukodaci Z, Aydin E, Goker K, Abuaf OK. A rare case report: Unilateral punctate palmoplantar keratoderma. J Clin Anal Med 2013;4 Suppl 1:46- 8 .

5. Biyik Ozkaya D, Tas B, Su O, UnalCakiter $\mathrm{A}$, Tosuner $\mathrm{Z}$, Demirkesen $\mathrm{C}$, et al. Unilateral linear punctate palmar keratoderma. J Dermatol 2014;41:449- 50.

6. Arif $\mathrm{T}$, Adil M, Amin SS, Saeed N. Unilateral striate-punctate keratoderma: An extremely rare presentation of punctate keratoderma. Indian J Dermatol Venereol Leprol. 2017; 83:589- 92. 